\title{
Evolution and Prospect of Dakar Drinking Water Consumption
}

\author{
Ndiouga Camara ${ }^{*}$, Ibrahima Mbaye ${ }^{2}$, Baba Ngom³ ${ }^{3}$, Déthié Sarr ${ }^{1}$, Séni Tamba3 \\ ${ }^{1}$ University of Thiès, Engineering Science Department, Thiès, Senegal \\ ${ }^{2}$ University of Thiès, Science and Technique Department, Thiès, Senegal \\ ${ }^{3}$ Polytechnic School of Thiès, Thiès, Senegal \\ Email: *ndiouga.camara@univ-thies.sn
}

How to cite this paper: Camara, N., Mbaye, I., Ngom, B., Sarr, D. and Tamba, S. (2019) Evolution and Prospect of Dakar Drinking Water Consumption. Journal of Water Resource and Protection, 11, 886-895. https://doi.org/10.4236/jwarp.2019.117054

Received: May 17, 2019

Accepted: July 27, 2019

Published: July 30, 2019

Copyright (c) 2019 by author(s) and Scientific Research Publishing Inc. This work is licensed under the Creative Commons Attribution International License (CC BY 4.0).

http://creativecommons.org/licenses/by/4.0/

\section{(c) (i) Open Access}

\begin{abstract}
In Dakar, there has been a considerable deficit in the drinking water supply for more than a decade. The distribution is poorly controlled in this region. And yet, there is no lack of supply sources or solutions. With a drinking water deficit of $300,000 \mathrm{~m}^{3} / \mathrm{d}$ to fill, the State of Senegal proposed two (02) options: firstly, the construction of a second Plan at Keur Momar Sarr on the Guiers Lake with a capacity of $75,000 \mathrm{~m}^{3} / \mathrm{d}$ coupled with a third pipeline between Keur Momar Sarr and Thiès (KMS3); secondly, the construction of a seawater desalination Plant with a capacity of $75,000 \mathrm{~m}^{3} / \mathrm{d}$. In this article, we studied the evolution of the drinking water consumption and the statistical data relating to population growth, which is the key element in the drinking water consumption evolution in Dakar. We were able to extract the equations from the trend curves that made it possible to predict a population growth. The results obtained with the equations and the curves show that the real needs for drinking water in Dakar are proportional to population growth.
\end{abstract}

\section{Keywords}

Drinking Water, Dakar, Evolution, Perspective, Consumption, Needs

\section{Introduction}

Senegal, a country of West Africa, is divided into fourteen (14) regions. It is located in the intertropical zone and is bordered on the north by Mauritania, on the south by Guinea Bissau and the Republic of Guinea; to the East by Mali and to the West by the Atlantic Ocean. The capital, Dakar concentrates a bulk of economic, political and administrative activities, and is facing an exponential demographic growth [1]. 
Dakar is characterized by a high human density. $23.2 \%$ of the Senegalese population live on $0.3 \%$ of the national territory. That corresponds to 3.2 million inhabitants in the last census carried out in 2013 [2]. For a long time, the drinking water supply system in Dakar has been facing increasing needs [3].

In fact, Dakar alone consumes $70 \%$ of the drinking water production on the whole enclosed area entrusted to the National Water Company of Senegal (SONES) by the government [1]. This high flow is explained by population growth, the development of economic activities and the extension of the city to the new urban poles of Diamniadio, Lac Rose and Rufisque. All those factors resulted in a daily deficit of $300,000 \mathrm{~m}^{3} / \mathrm{d}$ [4].

Thus, the state of Senegal committed to a major emergency program to solve the water problem in Dakar. It is a special program for drinking water supply in Dakar, launched pending the construction of the third Keur Momar SARR Plant and the commissioning of the seawater desalination plant. It consists of twenty-five (25) drillings and for the time being, twenty (20) are finalized, completed and delivered with an additional flow of twenty thousand cubic meters per day (20,000 $\mathrm{m}^{3} /$ day).

Another measure taken by the state is the disconnection of Pout market gardeners who use drinking water estimated between 10 and 12 thousand $\mathrm{m}^{3} /$ day, which corresponds to the consumption needs of a city like Saint Louis [5]. It is in this perspective that this article seeks to define a set of actions for improving the drinking water supply with requirements that guarantee the profitability and balance of the sub-sector of urban water supply. We will establish the equations, giving the real increase of the population per area, according to the trend curves; in order to have a better precision of the population growth relative to the drinking water consumption.

The current research consists of two fundamental axes:

- The diagnosis of the current state of the infrastructures;

- The assessment of past and current water needs as well as the resources to reach a reliable outlook for the evolution of drinking water consumption in

Dakar.

For such studies, it is very important to first use field data to exploit existing plans and to outline the drinking water supply sources.

This work will follow up and take into account programs, recommendations and conclusions from previous studies.

\section{Materials and Methods}

\subsection{Data Acquisition}

These are the digital plans of the SDE water system and of the consumption data from 2007 to 2009.

This data collection was carried out both at the level of SONES and at the level of other State services such as the DGPRE. These are essentially previous technical studies (hydrogeological studies, drinking water supply studies), annual ac- 
tivity reports from SONES and SDE and inventories of the infrastructure financed by the regional departments of the SDE.

These data are of paramount importance in the development of the water needs and resources review and the diagnosis of existing facilities [6].

\subsection{Treatment and Analysis (Numerical Statistics) of the Data}

The region of Dakar is composed of four (4) counties (Figure 1).

The analysis and treatment of digital data were facilitated by the Excel software which allowed us to draw figures and curves; which will make it possible to extract the drinking water consumption evolution equations of the region of Dakar.

The distribution and density of its population per county are shown in Figure 2.

For the situation of water supply sources, "Senegalaise des Eaux" (SDE) is linked to the State of Senegal by a contract and provides drinking water to populations in urban and peri-urban areas. It has eleven (11) regional management centres whereas the Dakar region has three departments (03) including 14 units of this study as shown in Table 1 [4].

\subsubsection{The Regional Management of Dakar 1}

The main drinking water supply sources of these units are constituted of Thiès reservoirs upstream via ALG pipelines [7]. The water consumption in 2009 of these units is estimated at: 2,604,700 $\mathrm{m}^{3}$ for Plateau Médina; 2,558,768 $\mathrm{m}^{3}$ for Grand Dakar; 2,446,720 $\mathrm{m}^{3}$ for Sicap Liberté; 4,347,748 $\mathrm{m}^{3}$ for Yoff and

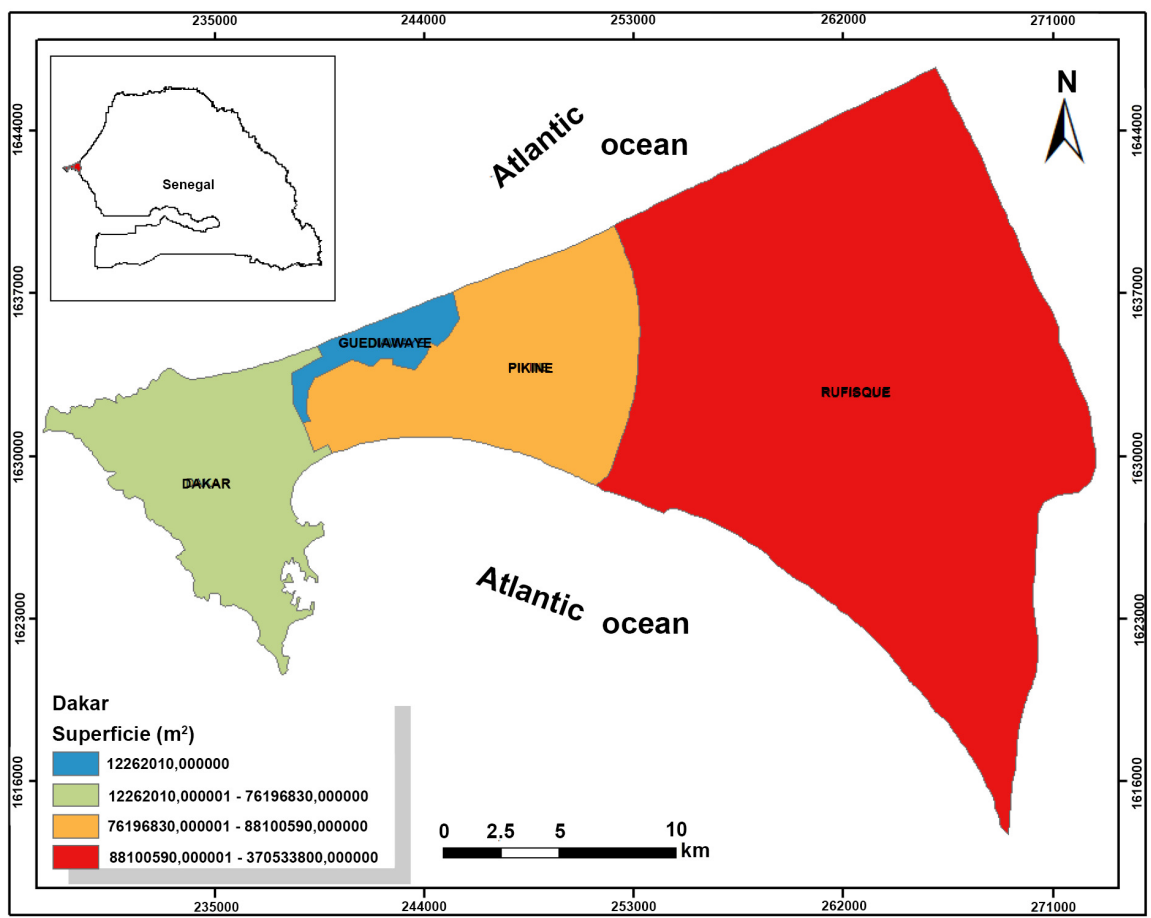

Figure 1. Departmental division of the Dakar region. 


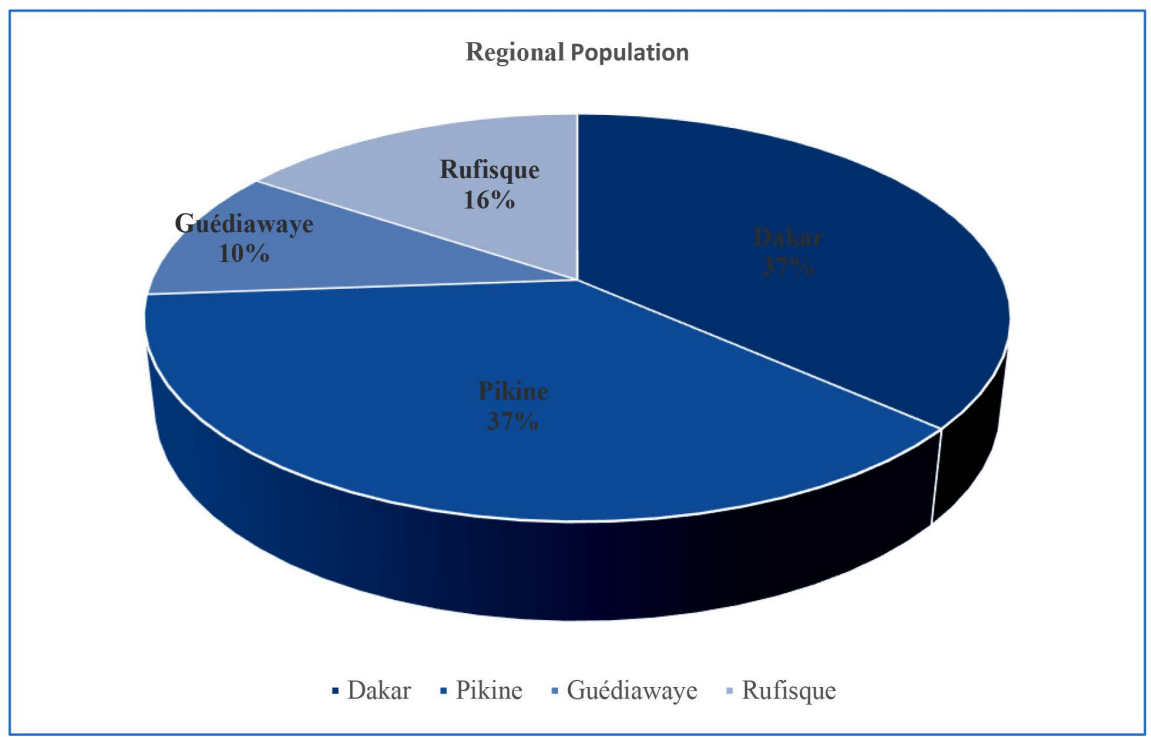

Figure 2. Distribution of Dakar regional population by department in 2013. Source: ANSD 2015.

Table 1. Distribution of the 14 units in the different Regional Management (RD).

\begin{tabular}{ccc}
\hline Regional Management & Attached Units & Units in the Regional Management \\
\hline DAKAR 1 & $\begin{array}{c}\text { Grand Dakar, Liberté, Front de } \\
\text { Terre, Grand Yoff, Plateau } \\
\text { DAKAR 2 }\end{array}$ & 05 \\
Guédiawaye 1, Guédiawaye 2, \\
Pikine, Parcelles, Thiaroye \\
RUFISQUE & $\begin{array}{l}\text { Rufisque, Bambilor, } \\
\text { Bargny, Sébikotane }\end{array}$ & 05 \\
\hline
\end{tabular}

3,182,007 $\mathrm{m}^{3}$ for Front de Terre [8]. In the last census carried out in 2002, the population of Dakar 1 is estimated at 221,438 inhabitants for Plateau Médina with a $1.6 \%$ annual rate of growth; 129,566 inhabitants for Grand Dakar with a 1.9\% annual rate of growth; 103,417 inhabitants for Sicap Liberté with a 1.5\% annual rate of growth; 182,073 inhabitants for Yoff with a 3.4\% annual rate of growth and 140,952 inhabitants for Front de Terre with a 1.7\% annual rate of growth [9].

\subsubsection{The Regional Management of Dakar 2}

The Regional Management of Dakar 2 provides water services in the suburbs of Dakar. The estimated water consumption of these units is $1,540,289 \mathrm{~m}^{3}$ for Guédiawaye 1; 3,175,570 $\mathrm{m}^{3}$ for the Parcelles Assainies; 5,466,938 $\mathrm{m}^{3}$ for Thiaroye; $1,490,756 \mathrm{~m}^{3}$ for Pikine and $1,683,378 \mathrm{~m}^{3}$ for Guédiawaye 2 [4] [8]. The population of these units, in the 2002 national census, was 175,282 inhabitants for Guédiawaye 1 with a $1.8 \%$ annual rate of growth; 234,294 inhabitants for the Parcelles Assainies with a $4.8 \%$ annual growth rate; 504,582 inhabitants for Thiaroye with a 5.7\% annual rate of growth; 113,560 inhabitants for Pikine with a $1.6 \%$ annual rate of growth; 176,950 inhabitants for Guédiawaye 2 with a $2.9 \%$ 
annual rate of growth [9].

\subsubsection{The Regional Directorate of Rufisque}

The water supply sources of these units are the same as those of Dakar 1 with the exception of B Point and Mamelles drillings. The water consumption of the Rufisque units in 2009 is: 3,854,336 $\mathrm{m}^{3}$ for Rufisque; 441,502 $\mathrm{m}^{3}$ for Bambilor; $877,409 \mathrm{~m}^{3}$ for Bargny and $1,436,271 \mathrm{~m}^{3}$ for Sébikotane [4]. The population of the Rufisque units, according to the figures of the last 2002 census, is estimated at 145,282 inhabitants for Rufisque with a $2.5 \%$ annual rate of growth; 43,015 inhabitants for Bambilor with a $4.5 \%$ rate of growth; 36,516 inhabitants for Bargny with a $2.5 \%$ annual growth rate and 28,582 inhabitants for Sébikotane with a $2.5 \%$ annual growth rate [9]. The Bargny, Sébikotane and Bambilor Units feed polarized localities and villages such as Sendou, Toubab Dialaw, Yene, Diamniadio, Dougar, etc.

\subsection{Population and Drinking Water Needs Assessment}

The drinking water needs assessment will be based on the Millennium Development Goals (MDGs). The targets of service rate in urban units are 100\% (\% of population); 100\% for Private water connections (BP) and 0\% for Standpipes (BF).

For the Privatewater connections (BP), the population's consumption needs are 55 liters/pers/day and for the FF, the population's consumption needs are 25 liters/pers/day [7]. The daily peak coefficient is equal to 1.1 or 1.3 in the following cases: small units 1.10 (pop < 100,000 inhabitants) and large units 1.30 (pop > 100,000 inhabitants). The hourly peak coefficient is 2 or 2.2 in the following cases: small units 2 (pop < 100,000) and large units 2.2 (pop > 100,000).

For the future population estimation, a Polynomial projection based on a correlation coefficient of 1 was used for the different units [9].

In this context, it is important to know what would be the most appropriate method for Dakar region.

The needs were estimated as follows:

Total domestic consumption (Cdtot);

Consumption for special connections $(B P)$ : future population Cons $B P$.

$$
\text { Cons } B P=P o p \times \tau d B P \times \text { Cons } S p B P
$$

With:

Pop: Total population in 2018;

$d B P$ : MDG desertification rate for the $B P$;

$S p B P$ Cons: Specific Consumption (1/d/hbt) for $B P$.

$$
\text { Cons } B F=P o p \times \tau d B F \times \text { Cons } S p B F
$$

With:

Pop: Total population in 2018;

$d B F$ : MDG desertion rate for the $B F$;

Cons $S p B F$ : Specific Consumption (1/d/hbt) for $B F S$. 


$$
\mathrm{Cd} t o t=\mathrm{Cons} B P+\mathrm{Cons} B F
$$

Public buildings and market garden consumption (Consep)

Based on the 2009 SDE consumption, analyses were made to determine the ratio (consumption of public buildings is equal to $16 \%$ of annual consumption. And the market gardening consumption is estimated at $12,000 \mathrm{~m}^{3} / \mathrm{day}$ ) [5].

This ratio will be used for future estimations:

Total industry consumption (Consî)

Based on the 2009 SDE's consumption, analyses were made to determine the ratio which is estimated at $11 \%$ of annual consumption (total industry consumption/total consumption).

This ratio will be used for future estimations.

Total unit consumption (Constot)

$$
\text { Constot }=C d \text { tot }+ \text { Consep }+ \text { Cons } i
$$

Daily needs with leaks $(B j)$

$$
B j=\frac{(\text { Constot })}{\eta}
$$

With:

Constot: Total consumption of the center;

$\eta$ : Network performance;

Daily Peak needs $(B p j)$.

$$
B p j=B j+C p
$$

With:

Bj: Daily needs with leakage;

$c p$ : Daily peak coefficient;

The Cph hourly peak coefficient of 2 or 2.2 is established as follows: small units (pop $<100,000) \rightarrow 2$ and a large one $($ pop $\geq 100,000) \rightarrow 2.2$.

The values above come from the formula:

$$
Q_{p h}=1.5+\frac{2,5}{Q^{0,5}}
$$

Thus the hourly peak flow $\left(Q_{p h}\right)$ is given by the formula:

$$
Q_{p h}=C_{p h} \times Q_{p i}
$$

With $Q_{p \text { s }}$ the daily peak flow.

\section{Results and Discussions}

According to the annual drinking water consumption curve in Dakar, there is an increase throughout the Region (Figure 3).

The counties of Pikine and Dakar are more populated with each $37 \%$ of the population of the region (Figure 2) [10]. Proportionally, we note that the evolution of consumption is more pronounced [7] [9].

But the county of Rufisque knows a major infrastructural improvement resulting from the will of the State to unclog the capital [11]. As a result, the 


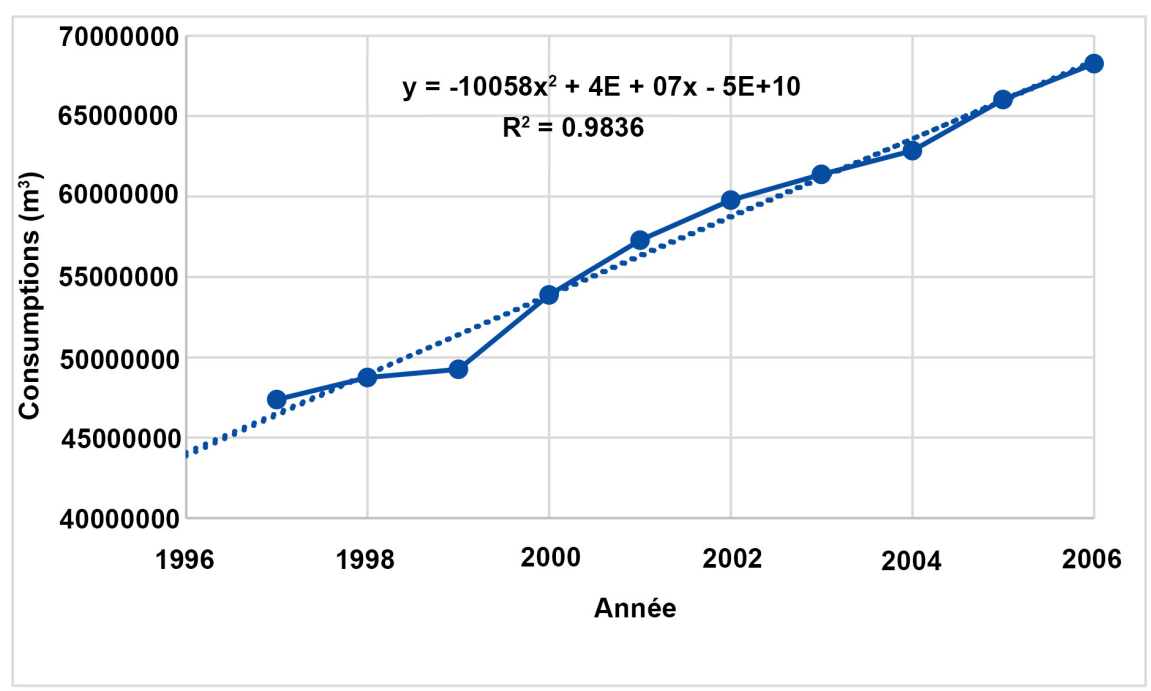

Figure 3. Dakar Region Annual Consumption from 1996 to 2006. Source: DGRPE 2010.

infrastructures they provide are not only a real attraction but also a demographic amplifier because of their very varied numbers and functions. Special attention must therefore be paid to the demographic evolution of Rufisque county (Figure 4) [12] [13].

Figure 4 shows that since 2004, Rufisque knows a considerable demographic evolution. The analysis of this evolution will make it possible to evaluate the level of involvement of the future population in drinking water consumption [14].

Since the end of the 1980s, the population has increased by $2.7 \%$ per year, due to the natural increase of the population, to reach 2,956,000 inhabitants in 2013. It is in the two most rural counties that growth has been the strongest between 2002 and 2013: Rufisque experienced population growth of $+6 \%$ per year and Pikine, $+4 \%$ per year [7].

In Rufisque, there are great disparities between the 12 municipalities. The three (3) municipalities of Rufisque concentrate the largest number of inhabitants $(221,000)$, i.e. $45.1 \%$ of the population. Finally, three-quarters of the population of the Department (77.4\%) live in urban areas [9].

Eventually, drinking water consumption evolution projection of the various counties is represented in Figure 5.

The comparison of the logarithmic, polynomial, linear and exponential mathematical models allowed us to choose the one that gives more precision with a correlation coefficient that is equal to 1 .

So, it is important to underline that Diamniadio urban county, Diamniadio industrial zone, the second university of Dakar and several other structuring projects that will eventually boost the development of the area, have been reinforced with the turnpike which allows people to make the trip Dakar-Diamniadio in less than 30 minutes. The strategic character of the area is revealed by the gradual establishment of businesses, but especially the construction of new housing. This fact that populations occupy the central position does not correspond 


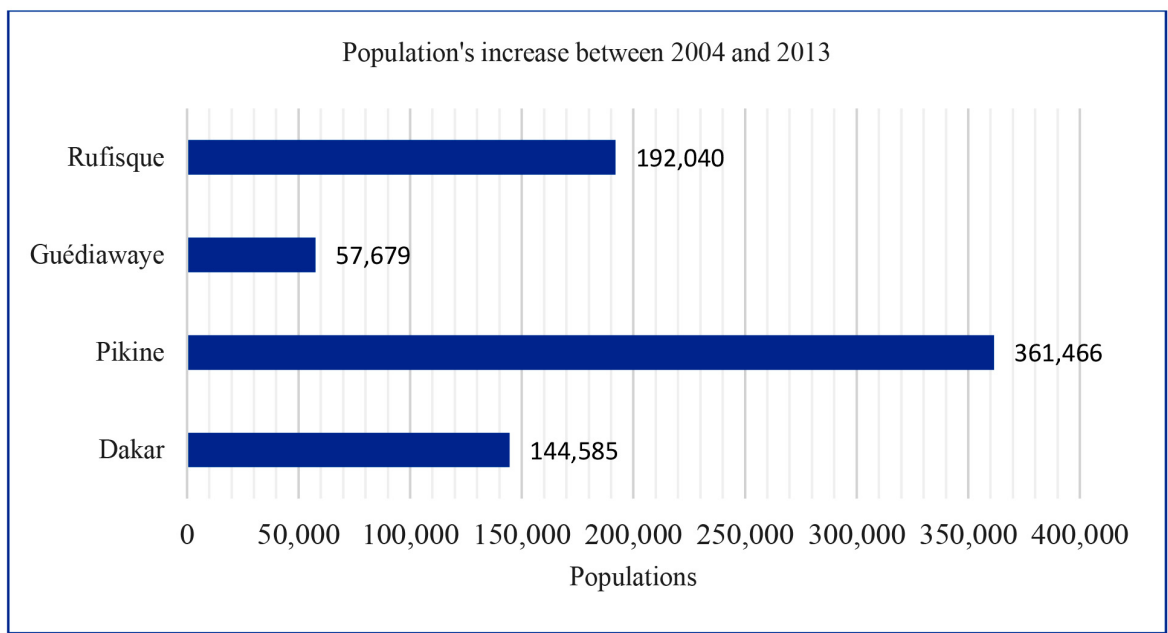

Figure 4. Evolution of the population of Dakar between 2004 and 2013.

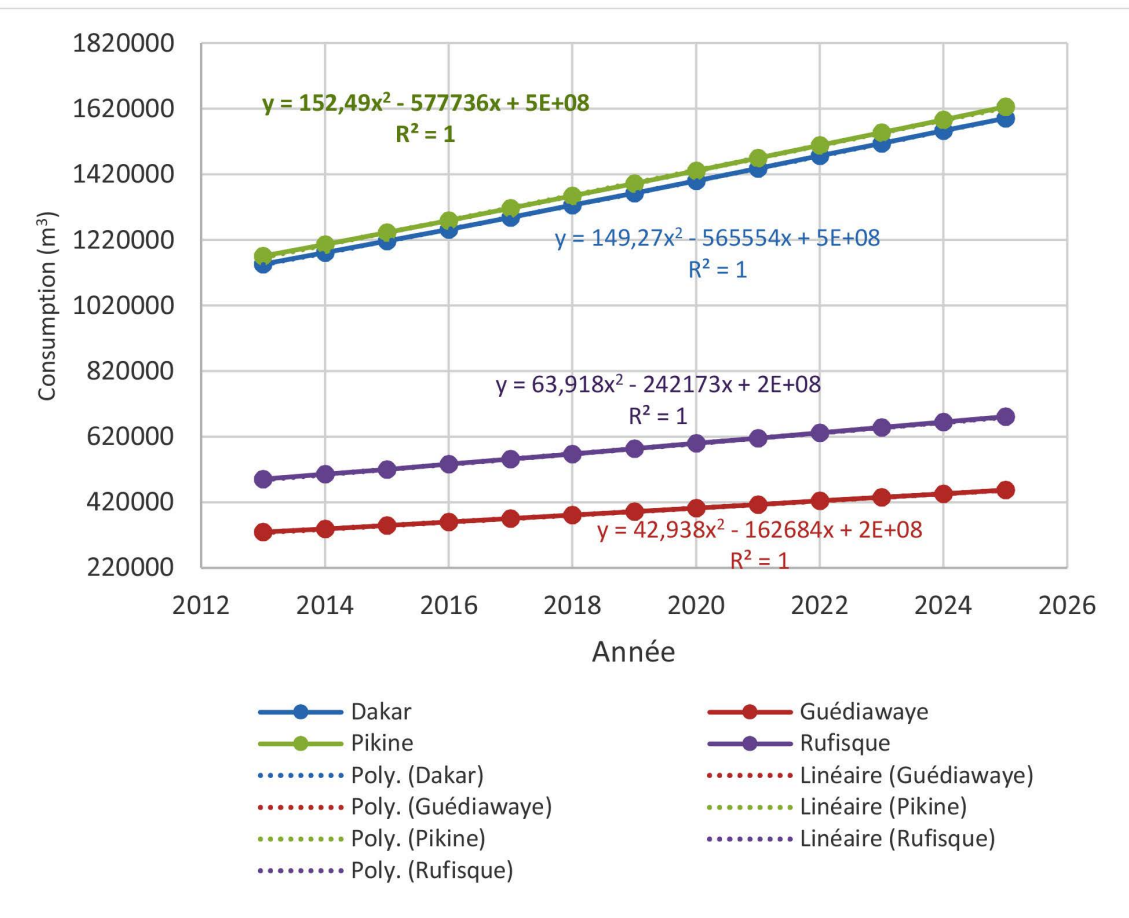

Figure 5. Comparison of the projection curves of the drinking water consumption of the different departments.

to the quantity of consumption of water which is mainly proportional to the population [15].

In the next few years, the demographic structure of Dakar will undergo much more changes than those currently observed, as illustrated by the equations above. The youth of the population is clearly a very important demographic change factor. The demographic factor is therefore the most important drinking water consumption factor. This approach, unlike the other approaches mentioned above, has given us more precision. Instead of having an overall accuracy 
of the region, this approach gives the advantage of having a specific accuracy for each department, which gave us more accurate results. And this precision, relative to the geographical position of the different departments in the region, will play a determining role on the flow distribution during the design of the drinking water supply network.

\section{Conclusion}

This study relevance and the results can be organized on three (3) levels. For research, the results of this article will catch attention both to the choice of the method and the need or not to take into account in the drinking water needs estimation, some consumers in the process of disappearance such as agricultural spaces, because of galloping urbanization. The parameters that determine water consumption at the city level are poorly known and few actors were interested in it when consumption was increasing. The actors have become increasingly aware that the demand of drinking water is a complex function, depending on many factors. In agreement on this subject, we can say that the mastery of the main actors, but also the careful estimation of the needs for drinking water, must be at the heart of the research work. And this is justified by the fact that the parameters on which drinking water consumption depends are not only difficult to follow, but they are in perpetual variation as well. Therefore, the factors identified by the statistical studies must be contextualised, redirected and adapted according to the study framework because, household equipments such as the economic dishwashers and washing machines, the economic sprinkle systems, remain very poorly developed in Senegal. But overnight, we can always expect abrupt changes in the factors influencing drinking water consumption.

\section{Conflicts of Interest}

The authors declare no conflicts of interest regarding the publication of this paper.

\section{References}

[1] Béture-Sétane (1988) Dakar Water Supply Reinforcement.

[2] Faye, S. (1995) Hydrodynamic Modeling of Aquifers of the North Coast between Kayar and Saint-Louis. The Impact of Future Withdrawals in Connection with the Water Supply in Dakar and Its Surroundings. Dakar.

[3] Faye, S. (1998) Modeling the Aquifer's Hydrodynamic Functioning of the Northern Coast of Senegal. Simulation of Additional Samples to Reduce the Deficit of Drinking Water Distribution in the Dakar Region. BRGM Hydrogéologie, 13-22.

[4] SONES (2012) Hydrochemical Study of the Quaternary Sand Table in Dakar Area.

[5] SONES (2018) Dakar Special Drinking Water Supply Program.

[6] COWI-Polyconsult (2009) Control of the Dakar and Subsurbs Production Facilities.

[7] DGPRE (2012) Basic Data, Resource Needs Assessment and Diagnosis of Existing Facilities.

[8] SDE (2012) Study Establish Master Plans and Database of Urban Hydraulics. 
[9] ANSD/RGPHAE (2013) Renaming the Population of Senegal.

[10] ANSD (2015) Report on the Census of Population of the Dakar Region.

[11] SDE/SONES (2013) Establishment of Master Plan, Phase 2 Report.

[12] SONES (2007) Mobilization of Alternative Water Resources for Irrigation in the Dakar Region. 79 p.

[13] Merlin, C. (2010) Drinking Water Supply Project for Cities in the Counties and Littoral Zone. Dakar.

[14] SETICO/CONCEPT (2013) Possible Variables for Water Resource Mobilization.

[15] Merlin, C. (2010) Drinking Water Supply Project for the Cities of the Central and Coastal Zones. Dakar, 386 p. 